\title{
ENTREVISTA AL DOCTOR RAÚl CARRANCÁ Y RIVAS
}

\author{
ABRIL USCANGA BARRADAS
}

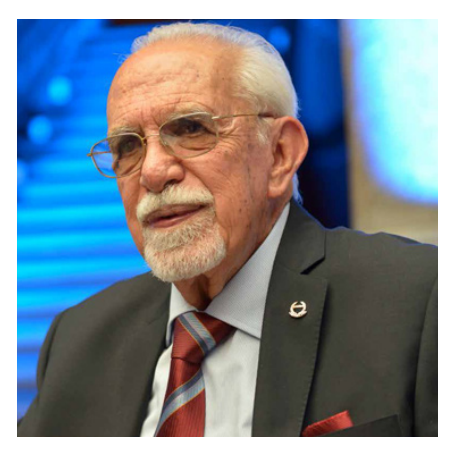

RAÚl CARRANCÁ Y RIVAS nació el 6 de septiembre de 1930 en la Colonia del Valle del entonces Distrito Federal. Su vida universitaria comenzó en 1948 con su ingreso a la Escuela Nacional Preparatoria del antiguo Colegio de San Ildefonso. El 20 de marzo de 1957 obtuvo el título de licenciado en Derecho por la Facultad de Derecho de la Universidad Nacional Autónoma de México con la tesis intitulada "La participación delictuosa, doctrina y ley penal", elaborada bajo la dirección de Raúl Carrancá y Trujillo, fungiendo como sinodales Juan José Gonzales Bustamante, Celestino Porte-Petit y Constancio Bernaldo del Quirós. El 17 de abril de 1974 con la tesis "Cárcel y penas en México, esbozo de un derecho penitenciario" le fue concedido el grado de Doctor por la misma institución, confiriéndole la distinción Magna Cum Laude, que le otorgó el sínodo correspondiente integrado entre otros, por Antonio Mar-

${ }^{1}$ Este documento constituye una transcripción de la entrevista realizada. Se ha revisado sin alterar el estilo coloquial propio de una conversación, considerando que esta característica enriquecería el texto que se presenta al lector. La entrevista fue realizada con la colaboración de Salvador Villaseñor Olguín y Yuriria Maryem Domínguez Juárez. 
tínez Báez, Alberto Truena Urbina y Luis Fernández Doblado. Su carrera como académico principió el primero de febrero de 1951, cuando al cursar el segundo año de la carrera de Derecho empezó a impartir clases de literatura universal en el plantel 2 de la Escuela Nacional Preparatoria y más tarde también impartió clases de lengua y literatura española. Posteriormente ingresó a dar clase como titular de tiempo completo en la Facultad de Derecho, impartiendo materias como Derecho Penal y Constitucional en el Posgrado. Paralelamente a la actividad académica, Carrancá y Rivas ha ocupado cargos dentro de la procuración y administración de justicia federal. El 16 de julio de 1950 fue nombrado agente del Ministerio Público Federal, ayudante de Francisco Gonzáles de la Vega quien fue en ese entonces el Procurador General de la República y, posteriormente, de 1987 a 1990 se le designó magistrado en el Primer Tribunal Federal Electoral. A lo largo de su trayectoria ha recibido innumerables testimonios de reconocimiento a su labor académica y a sus aportaciones a la ciencia jurídica, entre los que destacan la medalla al mérito académico por la Facultad de Derecho y las medallas en reconocimiento a sus años de labor docente.

\section{ENTREVISTA AL DOCTOR RAÚl CARRANCÁ Y RIVAS}

Dra. Abril Uscanga Barradas: Doctor, es un honor poder platicar con usted. De parte del Programa en Posgrado en Derecho de la UNAM y de la Revista le agradecemos que haya aceptado nuestra invitación y le damos la más cordial bienvenida.

Dr. Raúl Carrancá y Rivas: Muchas gracias, doctora Uscanga, por el honor que considero histórico debido a las circunstancias que está atravesando el mundo, en otras condiciones esta entrevista se habría realizado personalmente y ahora se realiza utilizando esta tecnología que impulsa la labor de la universidad y de sus altos funcionarios, como usted. Muchas gracias y es un honor.

AUS: Quisiera iniciar haciendo un acercamiento entre usted y nuestro público, por lo que me gustaría hablar un poco acerca de su vida académica como estudiante, así como académico. Sabemos 
que usted es hijo de quien fue un renombrado jurista, me gustaría preguntarle qué lo impulsó a estudiar Derecho y cómo era el ambiente estudiantil en aquellos momentos.

RGR: ¿Qué me impulsó a estudiar Derecho? En la educación de toda persona, no podría yo ser la excepción, hay un elemento de invitación o una condición relacionada con seguir el camino de quienes nos forman, en el caso de un servidor fue el seguir el camino de mis padres, concretamente de mi padre. Yo fui hijo único de tal forma que toda la atención y dedicación estaba concentrada en mi persona por lo que, desde muy pequeño, para no dejarme en la casa paterna, acompañaba a mis padres a distintos tipos de eventos. Recuerdo haber ido a conferencias de los maestros de mi padre a quienes él traía de España a México o bien de los profesores de nuestra universidad. Yo estaba entre el auditorio, calladito y oyendo, creo que esto fue influyendo en mi temperamento y sensibilidad, independientemente de que en la casa paterna escuchaba constantemente a mi padre hablar sobre Derecho. Repito, pienso que este fue un ingrediente básico para ir orientándome, fundamentalmente fue un proceso de invitación, se podría decir que "hijo de abogado, abogado". Llega el momento en que entré a la Facultad de Derecho y me encuentro con un ambiente determinado, propio y específico de cada generación. La caracterizaban cuatro palabras: la espontaneidad del estudiantado; éramos auténticos, no había elementos de réplica de otras condiciones o circunstancias, manifestábamos lo que éramos íntegramente, al cien por ciento. Aparte de esa espontaneidad se contaba con grandes profesores, esto es un ciclo que no termina ya que cuando acaba una generación de maestros llega otra y así sucesivamente, pero yo tuve la suerte de tener maestros de corte excepcional como Mario de la Cueva, mi padre, Carranca y Trujillo, Gonzáles de la Vega, Antonio Martínez Báez, Constancio Bernaldo del Quirós, Mariano Jiménez Huerta, entre otros. Gente de primera línea y categoría, muchos llegados de España por el problema político que ahí se había dado y otros de nuestra misma casa de estudios. Juntando estos elementos con la vocación e inte- 
rés del alumno, te encuentras con grandes profesores que disertan, hablan y manifiestan sus ideas. Cada generación tiene su sello, su "escudo", pero en mi caso eran personas excepcionales, cuyos libros siguen circulando y siguen siendo estudiados. Hay grandes profesores en la actualidad, pero hay generaciones marcadas por el sello de la historia. Quienes provenían de España tenían un conflicto de naturaleza mundial muy severo y traían consigo un coraje patriótico, un idealismo. Un ejemplo es Manuel Pedrozo quien impartió Derecho Internacional Público y quien llevaba consigo ciertas condiciones intelectuales y emocionales que matizaban sus cátedras y que fueron penetrando muy profundamente en nuestro espíritu. ¿Qué caracterizaba a mi generación? Yo digo que fue el ambiente: un ambiente espontáneo, sincero, sin réplicas de ninguna clase y en un diálogo abierto con una muy rigurosa disciplina que no era forzada, sino que se daba espontáneamente. Ese es el panorama que recuerdo.

AUB: En este contexto donde usted ya nos ha hablado de quienes fueron sus profesores, estos grandes juristas que influyeron en usted ¿hay alguno en particular a quien usted recuerde o, alguna experiencia que siga teniendo presente y que haya incidido en su pensamiento?

RGR: Sí, concretamente fue mi padre y maestro Raúl Carranca y Trujillo, lo digo con todo orgullo y honor, ya que su nombre está inscrito en la historia del derecho penal mexicano. Él fue discípulo de un jurista de renombre universal, Don Luis Jiménez de Asúa, ellos establecieron en México una escuela de Derecho Penal de corte valorativo, normativo, en la cual la cultura humanista predominada y sigue predominando. Ellos formaron un espíritu en este terreno, los recuerdo como profesores que influyeron de manera determinante. Yo no fui alumno de Don Luis Jiménez de Asúa, pero tuve el gusto de conocerlo y entablar conversación con él en un homenaje. Sus libros son excepcionales por la trayectoria que trazan en el pensamiento del estudiante, entonces alrededor de ellos había figuras excepcionales como Don Antonio Martínez Báez; Constan- 
cio Bernaldo de Quirós, criminólogo que también llegó con la inmigración española; Manuel Pedrozo; Rafael de Pina, quien fue mi profesor de Penal y que igualmente provenía de España. Profesores de una talla increíble. Se daba un detalle muy especial que no he constatado a través de los años más que en casos excepcionales, pero que entonces era casi la regla: te enseñaban derecho administrativo, mercantil, constitucional, internacional, todo eso con un sello profundo de humanismo jurídico, es decir, de cultura jurídica. Estaba presente lo más depurado de la cultura, partían de la base de que el derecho reconoce una normatividad ya existente, se impregna de ella y la manifiesta en la ley. En consecuencia, era un humanismo jurídico brillantísimo y expuesto de manera notable con una característica: todos ellos sin excepción eran extraordinarios expositores, magníficos oradores. También estuvo con nosotros, como profesor invitado, Don Constancio Bernaldo de Quirós, él ocupó un cargo político en el gabinete de Azaña, quien fue presidente de la República Española; así como el inolvidable maestro de derecho laboral Don Teófilo del Bueno. Se pueden repetir las generaciones con otras circunstancias y condiciones, pero respecto a la pregunta tan interesante que me plantea, respondo de acuerdo con el tiempo, condiciones y circunstancias que viví.

AUB: Muchas gracias, doctor, sin duda tiene usted una memoria prodigiosa. Es muy interesante conocer el contexto estudiantil que le correspondió, en ese sentido quiero hacer el paso desde su vida como estudiante hacia su vida como académico, lo reconocemos en el ámbito jurídico como un gran maestro con 70 años de carrera académica, con lo cual seguramente tendrá bastantes experiencias importantes y habrá formado a muchísimos juristas que actualmente se encuentren en la práctica de la profesión. Quisiera saber cuál fue ese momento en el que usted decide dedicarse a la academia y cuál fue el momento en que usted tomó la importante determinación de que la academia iba a ser su actividad primordial en el ejercicio de la profesión. 
RGR: Recuerdo el momento en el que detecté que la actividad política de mi tiempo poco tenía que ver con los más altos intereses académicos. Había profesores muy destacados que habían emergido de la universidad, pero se marcaba una diferencia radical entre el quehacer político y el quehacer académico. Lo puedo revelar a través de un episodio que quizás sea ilustrativo. Era yo agente del Ministerio Público del fuero común en la Procuraduría de Justicia de la Ciudad de México en 1968 cuando estaba presente el conflicto estudiantil, recuerdo que había muchos jóvenes estudiantes detenidos y presentando sus declaraciones ante el Ministerio Público, yo me sentí muy comprometido como universitario y como profesor, así que hablé con el entonces subprocurador y le pedí que habida cuenta de mi condición académica me dispensara de hacer cierto tipo de preguntas. Se pasaba un boletín o circular que decía: “¿Desde cuándo es usted comunista?, ¿cuánto tiempo ha tardado en digerir 'El capital' de Marx?, ¿por qué participa en este movimiento con tanta violencia?" y otras similares, pero dando por entendido que todo eso era cierto, en vez de indagar o averiguar. Me parecieron preguntas tendenciosas y capciosas así que le pedí al subprocurador que me dispensara de interrogar a los estudiantes, a esto me respondió que no, debido a que yo tenía una responsabilidad con el Estado, era agente del Ministerio Público y auxiliar del procurador, por lo que tenía que seguir prestando mis servicios. Días después presenté la renuncia alegando alguna condición familiar, personal, de salud o que era yo muy joven, pero fue el camino que me orientó hacia la universidad y hacia la actividad académica. Es interesante esto porque revela disonancias entre el deber ser académico y el ser social, como sigue siendo a la fecha. Nuestro gran reto es actualizar el deber ser académico a la realidad social, eso sí lo reconozco, pero siendo académico puro o bien con una vocación muy marcada por el derecho y por el mundo del deber ser jurídico, esto cuesta trabajo. Entonces ahí decidí que mejor me dedicaría a la investigación y a la cátedra jurídica. Sirva pues como un pequeño detalle de la vida de un servidor, anecdótico, del momento en el que tomé la decisión a la que usted acaba de aludir. 
AUB: Muchas gracias por compartirnos su experiencia, doctor. Dentro del marco de la profesión académica estos 70 años no son fáciles de decir, pero seguramente tal experiencia habrá implicado grandes retos. Quisiera preguntarle, ¿cuáles han sido los mayores retos que ha afrontado en la labor académica?

RGR: Los mayores retos se pueden concertar en lo siguiente. Guando fui designado junto con el director de la Facultad de Derecho, Miguel Acosta Romero, como magistrado del primer Tribunal Federal Electoral que hubo en el país, al igual que Edmundo Elías Musi, queridísimo profesor de la Facultad que fue director del seminario de Derecho Constitucional; recuerdo que un entrañable amigo, maestro de todos nosotros, Don Ignacio Burgoa Orihuela, se desconcertó mucho de nuestro nombramiento y dijo: "Pero ¿cómo se les ha ocurrido aceptar ese cargo? Han paseado ustedes la toga universitaria, la han llevado a un lugar francamente inapropiado y la están lastimando, la están zahiriendo y yo protesto solemnemente por eso". Enfureció mucho, era su costumbre periódicamente expresar su pensamiento por escrito así que divulgó un folleto en la Universidad, en la sala de maestros de la Facultad de Derecho, se distribuyó alegando lo dicho y estando en contra del Tribunal. Protesté debido a que estaba impregnado de un profundo idealismo y no creía de ninguna manera que en un cargo de tanta relevancia e importancia riñeran el Derecho y la práctica jurisdiccional; de tal forma que manifesté mi pensamiento y alguien mencionó: "Bueno, vamos a organizar un debate, van a estar presentes el doctor Burgoa y el doctor Carrancá y van a debatir sobre este punto". Se llevó a efecto el debate en el auditorio "Ius Semper Loquitur", ahí el maestro procedió a tomar la palabra, al igual que yo. Todo mi pensamiento lo manifesté basándome en un escrito notable de Cicerón que se llama "Pro Murena" en el cual Cicerón defiende los derechos jurisdiccionales y políticos de Murena, un personaje de su tiempo, alegando que la política y la actividad pública no se deben disociar del derecho y, que era fundamental la presencia del derecho en esa rama y espacio. Se llevó a cabo con cierta violencia, 
con iracundia, pero cada uno expuso sus puntos de vista, el doctor Burgoa era un hombre excepcional, de los grandes maestros que ha habido en la Universidad. Ese momento lo recuerdo como uno de especial interés, en relación con su pregunta.

Otro momento fue también cuando la Universidad entró en una huelga de 10 meses de inactividad, de parálisis total y la autoridad no hacía nada. Recuerdo que al procurador de ese entonces se le dijo: "Se han cometido ilícitos en la universidad, ha habido despojos que han sido denunciados ante el Ministerio Público"; él manifestó que por órdenes del presidente Zedillo la línea era primero el diálogo y la concertación y, el Derecho como último. Nosotros protestamos, el doctor Burgoa y yo dijimos: "No, primero debe ser el Derecho, que todo se lleve a cabo conforme a Derecho". La universidad estaba siendo ultrajada por ciertas personas del grupo disidente; no todos, pero sí algunos cometieron despojo de tal suerte que pedimos la presencia de la fuerza pública, no violando la autonomía universitaria, sino todo lo contrario, partiendo de la base de que en la universidad debía estar presente el Derecho. "Aquí debe de imperar el Derecho y no estamos en contra de la organización jurídica sino al contrario, la respaldamos y apoyamos por lo que pedimos que la autoridad nos devuelva lo que es nuestro." A las pocas horas de esta solicitud y petición ingresó la policía, sin violencia ni fuerza recuperó la universidad y entró Francisco Barnés de Castro. Recuerdo que el doctor Burgoa muy orgulloso decía: "Raúl, querido Raúl, hemos sido los cónsules que le han devuelto la universidad al país", fuimos los dos, acompañados de otros grandes profesores que hicieron eco de nuestra solicitud entre quienes recuerdo a mi entrañable amigo Julián Güitrón Fuentevilla, uno de los grandes civilistas que hay en México y promotor del derecho familiar. El doctor Burgoa se enorgullecía mucho de esto y fue otro episodio que marcó muy poderosamente mi vocación política y jurídica. El maestro, al recuperarse la Facultad de Derecho y todas las áreas de estudio e investigación de la Universidad, participó con un servidor en un acto público en reconocimiento de lo sucedido con alegría 
y jolgorio intelectual y académico, durante dicho evento ingresaron disidentes al Ius Semper Loquitur, interrumpiendo de manera violenta y amenazando con golpearnos. Alguien en ese momento dijo: "No pueden salir, tienen que retroceder porque si salen va a haber un enfrentamiento violento" así que fuimos retrocediendo y detrás del presidio del Ius Semper se encontraba un gabinete donde académicos y profesores acudían a vestirse para algún evento de relevancia. Entramos en el gabinete y nos percatamos que en la parte superior había una escotilla de metal por la cual salimos, recuerdo que el periódico Excelsior publicó una fotografía que tenía escrita: "Así salen los académicos frente a la violencia universitaria" y la mano del doctor Burgoa fue la primera que asomó para agarrarse del borde de la escotilla. Fue un momento muy importante de recuperación de la universidad a través de la actividad académica.

AUB: Esos recuerdos deben ser invaluables. Quisiera permitirme, si usted también lo considera pertinente, hacer unas preguntas de índole académico. Me gustaría conocer su opinión como profesor emérito, distinción importantísima que solo los más grandes académicos de nuestra universidad tienen, respecto de ciertos temas que están en la discusión nacional en materia penal, ¿considera usted que el Código Nacional de Procedimientos Penales se adecua a la realidad mexicana y ayuda eficazmente a la impartición de justicia en México?

RGR: En principio creo que no. Pienso que se inauguró un periodo caracterizado por la incertidumbre, la ineficacia y el desconcierto. Así mismo, creo en principio que es una reproducción de la legislación norteamericana, de los Estados Unidos de América, caracterizada por un tinte pragmático muy poderoso y fuerte. Creo que ha sido negativo. Tengo en mi biblioteca el Código Nacional de Procedimientos Penales y, en relación con la pregunta que usted hace, me remito a los artículos 255 y 256 en los cuales se alude al criterio de oportunidad. Para no entrar en materias técnicas, el criterio de oportunidad consiste en que cuando el Ministerio Público lo considera conveniente y adecuado se maneja la figura del testigo 
protegido, es decir, una persona que puede dar testimonio de lo que ha pasado, de lo que ha visto y de lo que ha sucedido, pero bajo ciertas condiciones, por ejemplo, que la pena no sea por un delito violento y que no exceda de los 5 años, entre otros requisitos precisados por el Código. El testigo protegido, como su nombre lo indica, está bajo la protección de la justicia en el sentido de que todo lo que diga le va a ser favorable para disminuir o atenuar su responsabilidad penal. Resumidamente esta es la característica del testigo protegido, claro que habría de leerse con mayor cuidado el Código, ya que esta no es una clase de Derecho Penal ni de Derecho Procesal. La gran pregunta que surge aquí es la siguiente: ¿qué acaso la responsabilidad, aunque no se haya cometido un delito violento, aunque la pena no exceda de 5 años, se puede disminuir porque yo narro lo que he presenciado? ¿qué tiene que ver esto con la culpabilidad? La culpabilidad la califica el juez con base en otro de elementos, condiciones y circunstancias. Esto tiene el sello de un pragmatismo muy fuerte, muy grande, pero no tiene que ver con valores jurídicos fundamentales y eso es por lo que se ha hablado de la puerta giratoria debido a que el sistema es muy endeble, es imperfecto y podría perfeccionarse, pero no obedece a nuestra tradición jurídica. Habrá que buscar inspiración en otras fuentes de motivación procesal y penal porque lo que digo nos es ajeno, no tiene relación con nuestra tradición de tipo jurídico y de tipo penal. Por lo que, a mi parecer, esta figura ilustra mi crítica y pone de manifiesto algo que no opera en la técnica adecuada: que la culpabilidad puede disminuir o desaparecer por una serie de circunstancias y de condiciones relacionadas con el elemento volitivo, con las causas determinantes de la presencia de la culpabilidad, pero no por la denuncia que haga de los hechos y que con base en eso la culpabilidad desaparezca o disminuya. Puede ser muy útil dentro de un concepto de pragmatismo jurídico, se pueden obtener resultados muy prácticos, pero a costa de traicionar el deber ser fundamental que es esencial en la gran tradición jurídica del derecho que hemos heredado y que conforma nuestra razón de ser jurídica. Este 
delicado problema se encuentra acompañado de una reforma muy imperfecta en la cual, entre otras cosas, se consagra la presunción de inocencia, pero se deja la prisión preventiva. Esto nos dice que puedo ser encarcelado preventivamente antes de que haya justicia o sentencia del juez y en esto veo una incongruencia. Esto también tiene que ver con el pragmatismo. Igualmente está presente el arraigo: me arraigan, puede haber condiciones especiales para esto, pero aún no hay sentencia, hay presunciones de culpabilidad, entonces ¿cómo opera esto con la fórmula de que la presunción de inocencia es válida, lo cual está consagrado en la Constitución? Si soy presuntamente inocente, ¿cómo puede decirse que soy un individuo sujeto al arraigo a la prisión, aunque sea preventiva? Encuentro muchas incongruencias que no encajan en una armonía jurídica consistente, sólida y fuerte. En suma, me parece que es un sistema que no ha dado los resultados que se quieren, sino que ha permitido la filtración de muchas injusticias, de muchas operaciones jurídicas que no obedecen estrictamente a la técnica y a la razón de ser del derecho y que deben ser revisadas y, en su debido caso, modificadas de manera profunda, seria y directa.

AUB: Muchas gracias, doctor. En ese mismo sentido, hablando de lo conocido como la puerta giratoria, ¿`será que esto fortalece el sistema penitenciario mexicano?, ¿cuál es su opinión al respecto?, ¿qué opciones tenemos para la reinserción social?

RGR: Yo contestaría su pregunta partiendo de que usted habla de reinserción social contemplada en el artículo 18 constitucional. La readaptación social que viene desde la Escuela Positiva y corrige algunas, no desviaciones, sino manifestaciones muy rígidas de la Escuela Clásica presidida por Francisco Carrara. Por ahí va el tema vertebral y fundamental de la pregunta que usted manifiesta. Respecto al objeto del derecho y su función se habla mucho del funcionalismo jurídico-penal, es una gran corriente que está en boga y que se ha manejado como otras tantas que giran en torno a la preocupación de los investigadores del Derecho. El funcionalismo penal establece cual es la función principal del derecho penal y que 
lo más fuerte del derecho penal se encuentra en las penas privativas de la libertad independientemente de otras penas de tipo económico. La función primordial del derecho penal es reparar el daño no económicamente, sino jurídica y moralmente desde el punto de vista de la defensa de la sociedad encarcelando a esta persona que ha cometido un delito, privándole de la libertad. Dentro de la cárcel se supone debe operar el artículo 18 constitucional el cual trata sobre la readaptación social que usted ha citado; sin embargo, esta no existe, es una utopía. Al acudir a las cárceles se denota que son un infierno, salvo honrosas excepciones. La readaptación social es un mito, quien la defienda está diciendo algo que no conoce y no sabe; habría de readaptar a través de una revaloración de la persona que ha delinquido, pero en realidad se le readaptada dejando de lado lo valorativo, lo normativo y hasta lo moral. Supongamos que sí opera la readaptación social, es decir, ya fui readaptado, quedé químicamente puro y se me regresa al seno de la sociedad en la cual delinquí, pero ¿cuál es esta sociedad? Es una sociedad criminógena, regida por las reglas consumistas, una sociedad predominantemente capitalista con una desviación del capitalismo aberrante en la cual los valores están por los suelos, desconocidos, oprimidos, despreciados; de tal manera que aprovecho para presentar un símil: es como si yo estuviera enfermo del pulmón, soy curado, ya no tengo problema alguno y soy regresado a la misma mina contaminante y contaminadora donde adquirí esta enfermedad, se vuelve un cuento de nunca acabar. El sistema penitenciario es un fracaso profundo y rotundo por esta cuestión. Esto sucede no solo en México, sino en el mundo entero, las cárceles no han dado el resultado que se esperaba de ellas y mucho menos la pena capital, de la cual no soy partidario, soy abolicionista. Pero la cárcel a fracaso de manera rotunda, creo que esto nos consta y lo sabemos por información, por experiencias o por noticias. Entonces, si la cárcel ha fracasado ¿cuál es la función del derecho penal?, el derecho penal está en crisis en México y en el mundo entero razón por la cual un servidor ha hecho propuestas en distintos congresos e incluso me encuentro escribiendo un libro sobre la que denomino "teoría revisionista del derecho penal”. ¿Qué 
solución daría yo a esto?, no es fácil hallar una solución, aunque en el propio problema está la semilla de la solución, pero hay que revisarlo ya que el camino que se está llevando actualmente no es el correcto. Poniendo otro ejemplo, el Chapo Guzmán se encuentra encarcelado, pero ¿de qué ha servido? No se ha acabado el narcotráfico, todo va adquiriendo el toque de una especie de venganza, se deja de lado una serie de derechos fundamentales. Soy partidario de que al que se le priva de la libertad no se le ultrajen estos derechos ya que tiene dignidad así sea la peor persona, por lo tanto, hay que buscar el camino de la rectificación moral y espiritual. Esto es algo muy complicado, es todo un reto y por eso hay que estudiar para reconocer cómo las cárceles han fracaso, para reconocer que el sistema penitenciario es lo mismo que nada, que no opera ni sirve por ser un absoluto y rotundo fracaso, para sobre esta base tratar de ver posibles soluciones; esto implica un esfuerzo enorme en el cual se deben comprometer las universidades públicas del país, principalmente nuestra máxima casa de estudios. Esta es mi visión del derecho penal y penitenciario que se encuentra en una crisis absoluta. Hay que pensarlo, la cárcel no ha dado los resultados que tiene que dar: no bajan los índices de criminalidad, no se logra un resultado positivo, la reeducación de los reclusos es utópica y absurda junto con una serie de problemas de disciplina con el narcotráfico, la violencia, las fugas y los homicidios presentes en las prisiones; es algo espantoso y no es el camino.

AUB: Le agradecemos que nos haya comentado no solo el estado y situación del sistema penitenciario, sino también las propuestas que nos otorgó. Esperaremos con muchísimo gusto su libro para poder leer sus opiniones al respecto. En este mismo tenor, doctor, quisiera solicitar su opinión acerca de la consulta popular para el enjuiciamiento de los expresidentes y los plazos de prescripción de los delitos.

RGR: Yo centro la pregunta en una circunstancia o condición que todos nosotros conocemos, el hecho es que la Corte se pronunció sobre el particular. Hay una Ley de Consulta Popular que tiene correspondencia en la Constitución; partiendo de esta base, la 
consulta popular es constitucional porque esta la establece, además de existir esa ley que fija los términos, plazos y condiciones. Con base en ello le llegó a la Corte una pregunta; lo primero que se dijo fue que era inconstitucional, pero apoyado en lo previamente dicho yo no lo veo así. Asimismo, en la pregunta que se le plantea a la Corte se dan nombres concretos y específicos, eso me desconcertaba mucho ya que se volvía una especie de acusación directa, como una especie de venganza; se deben investigar las circunstancias y condiciones ya que es una averiguación previa, posteriormente vendrán los nombres. La corrección de la Corte me parece por demás acertada, averigua e investiga todo lo que tenga que ver con los posibles responsables de una serie de anomalías y de hechos contrarios a la ley sin establecer nombres, se partirá de esta base y el Estado hará lo que crea conveniente. Centro la pregunta que usted ha formulado en la acertada resolución de la Corte, algunos la han criticado diciendo que es una barbaridad, yo no lo veo así. En primer lugar, es constitucional; en segundo, quita el señalamiento personal directo para dejarlo en el terreno de una indagación de hechos para ver cómo van surgiendo los posibles responsables de esos hechos ilícitos que se han cometido en ciertos momentos de la historia del país. Dicen que el pueblo opinó mal, aun así, la figura de la consulta popular está contemplada en la Constitución así o se quita de la Constitución o se abroga la Ley de la Consulta Popular, ambos cuerpos legales vigentes que dan solidez al tema. Creo que la consulta puede operar, habría que esperar para saber en qué condiciones se realizará la consulta y posteriormente, cuando tengamos un resultado, el Estado sabrá de qué manera actuar, basado en la Constitución y en la Ley de Consulta Popular, pero me parece lo más acertado para un camino que no tiene por qué llevar el sello de la venganza, del enfrentamiento personal como se observaba al señalar nombres concretos. Primeramente, se deberá investigar lo que tenga relación con los responsables de hechos contrarios al derecho, acaecidos en tal momento y dentro de estos responsables puede haber expresidentes o no, altos funcionarios o no. 
AUB: Gracias por su opinión, doctor. Ha sido muy grato el escucharlo, lo hemos seguido a través de sus columnas semanales, labor que usted realiza y de la cual seguramente podrá comentarnos un poco más. Además, sabemos que usted tiene una obra muy extensa por lo cual quisiera preguntarle, ¿qué libros son los más representativos de su pensamiento? Es decir, si alguien quiere conocer al académico Raúl Carrancá y Rivas, ¿qué libros debe de leer?

RGR: Querida amiga, libros hay millones. Un amigo mío decía: “Sabes cuántos libros se publican a diario?, no alcanza una vida". De todas las novedades, libros que no he leído, libros que tengo que releer, no me alcanzaría una vida, no dormiría de la cantidad, del torrente de libros. Frente a este hecho evidente y real, en cuanto al Derecho para mí ha sido fundamental un libro clásico de clásicos: la obra de Luis Jiménez de Asúa, del criterio de su obra se desprende una serie de reflexiones con valor normativo, cultura y humanista del derecho penal. Así ha sido el sello de mi obra y las características de mi quehacer académico: un sello humanista, cultural y normativo, devolviendo al derecho penal la grandeza original como expresión y guardián de una cultura superior. En otro sentido, entre las derivaciones que tiene la obra de Luis Jiménez de Asúa se encuentra la obra de mi padre quien fue su alumno, obra muy vasta de la cual, en parte, soy coautor. Esa es la línea seguida por Luis, por sus discípulos y sus orientadores. Hablando del humanismo y particularmente del humanismo literario, cada individuo se conforma por los libros que ha leído, cada generación tiene sus libros así que, si me pregunta cuáles eran los libros típicos de mi generación, no van a ser los mismos de su generación, ni los de mis alumnos; van cambiando, pero hay libros que quedan como monumentos, como puntos de constante reflexión. En este orden de ideas, por mi formación me apegué muchísimo a la llamada generación del 98 de las letras españolas: José Ortega y Gasset, Miguel de Unamuno, Gregorio Marañón; novelistas, artistas, con grandes novelas excepcionales que hoy son clásicas. Alguien decía: "Hay que volver a los clásicos" y completaba su pensamiento diciendo "yo ya no leo libros 
nuevos, releo los libros que se han nublado y opacado en mi memoria". Esto es fundamental porque usted me pregunta qué libro leí en el año 55 y probablemente le podría dar el nombre, aunque, salvo que tuviera una memoria excepcional, solamente tengo una imagen panorámica de ese libro que deberé volver a leer. Se que hay libros escritos recientemente que son muy importantes, lo reconozco, pero me apoyo principalmente en lo que ya está hecho, en lo que se encuentra consagrado y posteriormente en novedades. Me atraen, quizá por la profesión jurídica, las novelas históricas, una muy conocida que alguna vez pensamos debería ser propedéutica en la Facultad de Derecho, escrita por la gran novelista inglesa, nacionalizada norteamericana, Tylor Caldwell es "La columna de hierro, la vida de Cicerón", novela en la cual se narra la vida de un hombre notable y esto me atrae mucho porque no me pierde en la divagación de la fantasía, poesía o lirismo, sino que me ubica en una realidad concreta y es lo que a mi temperamento corresponde y atrae profundamente. Esto es lo que le puedo decir en lo particular. Es ilustrativo el comentario que di al inicio, no recuerdo el número exacto, pero usted se iría de espaldas si supiera la cantidad de libros que se escriben a diario. Sería imposible terminar, no podría desayunar, comer, cenar ni dormir, todo su tiempo se ocuparía en leer. Es algo terrible, es una carga cultural abrumadora, aparte de tener que distinguir lo bueno de lo malo, lo que deja y lo que no, pero yo creo que lo esencial es volver a los textos fundamentales, no olvidarlos, releer lo que está un poco nublado en la memoria, pero que tiene que ver con obras maravillosas de la literatura y siempre tener presentes las fuentes clásicas del pensamiento filosófico, literario y cultural.

AUB: Me voy a arriesgar a hacerle una pregunta, doctor. Yo sé que usted es una persona muy modesta, pero quisiera preguntarle ¿hay algún libro de su autoría que nos recomiende?

RGR: Claro, de Derecho me atrevo a recomendar un libro editado por Porrúa intitulado "El arte del Derecho" ya que pienso ahí he establecido mi pensamiento de manera clara y concisa. Creo 
que este es un libro donde quedan trazadas líneas de pensamiento que he tratado de desarrollar que son básicas y fundamentales, que trazan una ruta de investigación, de meditación y de expresión de las ideas.

AUB: Muchas gracias por esa recomendación, doctor. Estoy a punto de terminar la entrevista, no quisiera agotarlo y mucho menos extenderme más ya que sé que usted tiene una agenda bastante ocupada y le agradezco muchísimo que nos haya dado este tiempo. Quisiera hacerle una última pregunta que es más una petición, ¿podría regalar algún consejo o consejos para los jóvenes académicos que aspiramos a algún día convertirnos en grandes maestros como lo es usted?

RGR: Me abruma su pregunta ya que solamente puedo responder desde el punto de vista de mí experiencia, así que con toda modestia daré mi opinión al respecto, sintiéndome muy distinguido por la pregunta y por lo que representa. Yo pienso que el jurista se debe de formar no solo en apego a la ley, sino al espíritu de la ley. No estoy diciendo nada nuevo, pero hay que buscar la esencia de la ley. ¿Cuántos hay que se quedan en la mera forma, en la mera expresión formal, en la letra? Quizá lo ilustra mejor lo que decía Calamandrei, si la memoria no me falla, que comparaba la lectura de la ley, y me atrevo a decir de cualquier texto jurídico, con poner las yemas de los dedos sobre las teclas del piano; decía que todos lo podemos hacer, comparando esto con la profesión que tenemos de juristas, todos podemos poner las yemas de los dedos sobre la letra de la ley, presionamos un poco y hacemos ruido, pero hay uno que otro excepcional que busca la esencia, la entraña, la sustancia y es el gran pianista, comparando con un músico. Saca el espíritu de la ley y ese es el verdadero derecho. Para mí, lo que hay que hacer es buscar el fondo en la doctrina, de forma coloquial: lo que hay entre línea; en la ley es buscar su razón de ser, lo fundamental. La ley es importantísima, pero es apenas el inicio de una reflexión, es una pauta para reflexionar. La ley menciona una variedad de cuestiones, pero hay que ver por qué lo dice y cuál es la motivación. Yo 
creo que es el camino para ser un gran profesor y transmitir como académico un mensaje. Esa es mi posición personal.

AUB: Le agradezco, doctor. Ha sido un honor escucharlo, tanto para mí como para el Posgrado y la Revista del Posgrado en Derecho de la UNAM. Estamos muy agradecidos de que haya tenido el tiempo para otorgarnos esta entrevista y extender su pensamiento y conocimiento a los demás. Ha sido un gran placer, doctor, y esperamos contar con usted en un futuro, en otra entrevista si su agenda se lo permite.

RGR: El placer y el honor ha sido mío. Aprovecho la oportunidad para felicitar a la maestra Abril Uscanga por la brillante labor que realiza en la Revista, es usted voz y expresión Académica de la División de Estudios Superiores del Posgrado de nuestra Universidad, que está empeñada en un reto gigantesco por los días que estamos viviendo de pandemia junto con la Facultad de Derecho, es una labor excepcional y este es el camino para que la Universidad siempre esté presente, viva, latente y compartiendo ideas; no enseñando, sino presentado ideas para que se rectifiquen, se comenten, se modifiquen. Gracias queridísima doctora, el honrado soy yo y nuevamente mil felicitaciones, reitero mi reconocimiento por su obra, su presencia y su labor tan ilustrativa e importante.

AUB: Doctor, le agradezco. 